\title{
Teoria, metodologia e história ensinada: miradas a partir do Pibid
}

\author{
Theory, methodology and History \\ teaching: ways of looking from Pibid
}

Carmem Zeli de Vargas Gil ${ }^{*}$

Caroline Pacievitch**

Mara Cristina de Matos Rodrigues ${ }^{\star * *}$

\section{Resumo}

O artigo propõe reflexões sobre o Ensino de História na interseção com a Teoria e Metodologia da História, pensada como parte indissociável do planejamento de aulas de história na educação básica. Analisa-se uma proposta de aula desenvolvida no âmbito do Pibid, envolvendo temas da história da África e o recurso de histórias em quadrinhos. A hipótese é a de que problemas metodológicos, como a crítica documental, e teóricos, como configuração/refiguração de sentido e "função autor", estão associados à didática desenvolvida pelos pibidianos, mesmo que tenham permanecido implícitos em seus planejamentos e relatos de experiência prática. Complementam a análise considerações em torno da dimensão política da histó-

\section{Abstract}

This paper proposes reflections on the Teaching of History in the intersection with the Theory and Methodology of History regarded as inseparable from the history class planning in basic education. We have analyzed a class proposal developed in Pibid involving topics of the history of Africa and using comics as a resource. The hypothesis founding our reflections is that methodological and theoretical problems about historical knowledge are currently linked to the didactics developed by 'pibidians', even though they have remained implicit in their class planning and practical experience reports. This analysis has been complemented with remarks about the political dimension of history, whose social role includes the creation of conditions that

\footnotetext{
* Doutora em Educação pela Universidade Federal do Rio Grande do Sul (UFRGS). Professora da Faculdade de Educação (Faced) da UFRGS. Porto Alegre, RS, Brasil. carmemz.gil@gmail.com ** Doutora em Educação pela Universidade Estadual de Campinas (Unicamp). Professora da Faced/ UFRGS. Porto Alegre, RS, Brasil. pacievitch@gmail.com

*** Doutora em História pela Universidade Federal do Rio Grande do Sul (UFRGS). Professora do Instituto de Filosofia e Ciências Humanas da UFRGS. Porto Alegre, RS, Brasil. mara.rodrigues@ ufrgs.br
} 
ria, cujo papel social inclui a criação de condições para a distribuição mais igualitária dos bens culturais e a garantia do acesso e construção de conhecimentos em aula.

Palavras-chave: Ensino de História; Pibid; Teoria e Metodologia da História. favor a more egalitarian distribution of cultural assets, as well as the guarantee of access and construction of knowledges in classroom.

Keywords: History Teaching; Pibid; Theory and Methodology of History.

Compartilhar a docência é, por princípio, realizar o trabalho educativo com alguém, dispondo-se a dividir ideias, experimentar projetos de forma coletiva e ser autor sem a implicação particular de propriedade sobre algo. No sentido etimológico, docência tem suas raízes no latim docere, que significa ensinar, indicar, dar a entender. A docência como atividade profissional exercida em pares tem, na perspectiva do Parecer CNE/CP no 3/2006, um conceito mais amplo, que envolve também:

a participação na organização e gestão de sistemas e instituições de ensino, englobando: I - planejamento, execução, coordenação, acompanhamento e avaliação de tarefas próprias do setor da Educação; II - planejamento, execução, coordenação, acompanhamento e avaliação de projetos e experiências educativas não-escolares; III - produção e difusão do conhecimento científico-tecnológico do campo educacional, em contextos escolares e não-escolares. (Brasil, 2006, p.6)

O professor ensina porque confia que o outro aprende e porque acredita que o conhecimento ensinado é importante. Assim, ao ensinar história - preocupação central deste artigo - questões cognitivas e de cidadania não se separam. Consequentemente, historiografia, teoria da história e didática da história se transpassam de forma mais ou menos consciente nas tomadas de decisão dos professores sobre a seleção de conteúdos, os recursos e estratégias metodológicos utilizados e os objetivos a atingir. Portanto, o professor de história é um intelectual que, ao tomar decisões que conduzem seu trabalho, indica caminhos para os estudantes recorrendo a inúmeros artefatos culturais à sua disposição e, não raro, passa por questões que mobilizam ideologias e afetos.

As reflexões propostas neste artigo se constituem a partir da trama de ideias sustentadas por nossas vinculações como professoras e pesquisadoras em história e ensino de história e, mais recentemente, à atuação no Subprojeto 
História do Programa Institucional de Bolsa de Iniciação à Docência (Pibid) na Universidade Federal do Rio Grande do Sul (UFRGS). O texto que segue se baseia no acompanhamento e orientação de um grupo de bolsistas de Iniciação à Docência do Pibid em uma escola pública de Porto Alegre, no período de um ano, quando nos encontrávamos semanalmente, ora com os bolsistas, ora com a escola e ora entre nós professores da universidade para tecer o que seria nosso subprojeto.

Atuando nas escolas estaduais de Porto Alegre desde 2010, o Subprojeto História do Pibid da UFRGS iniciou em 2014 um projeto de 4 anos em que se pretende articular o trabalho com professores da Área de Ensino de História e de Teoria e Metodologia da História. Trata-se de uma iniciativa interdepartamental que reflete as preocupações em comum sobre a formação de professores de história: a necessária articulação entre os distintos conhecimentos que professores mobilizam quando ensinam. Nos debates sobre formação de professores, há os que defendem a prevalência do conteúdo, enquanto outros acreditam que é preciso, em primeiro lugar, dominar técnicas e métodos de ensino, já que o conhecimento estaria acessível "a um clique” de distância. Não nos parece frutífero, porém, trabalhar apenas sobre as dualidades entre a racionalidade prática e a racionalidade técnica que povoaram (povoam?) o debate sobre formação de professores (Monteiro, 2007).

Assim, a proposta do Subprojeto História rejeita a escolha por um ou outro lado, apostando que a formação de professores de história compreende inúmeras variáveis que não podem ser reduzidas a uma lista de habilidades. Afinal, a complexidade dos processos de ensinar e aprender história se relaciona com a amplitude de experiências vividas no contato e na construção de culturas históricas (Rüsen, 2007). Conforme se tem apontado cada vez mais, a história "não deve e não pode confundir-se com o simples aprendizado de conteúdos, mas deve perseguir a possibilidade de adquirir competências específicas capazes de fundamentar uma reelaboração incessante da experiência temporal com relação às experiências passadas" (Guimarães, 2009, p.49). Mesmo assim, ao estabelecer projetos político-pedagógicos dos cursos e planos de disciplinas, alguns aspectos mínimos são indicados pela legislação vigente e pela literatura sobre formação de professores. É importante que, entre outros aspectos, a formação inicial proporcione conhecimentos sobre o ofício do historiador e sobre a historiografia, que ofereça oportunidades de analisar 
processos de constituição do saber histórico escolar, que amplie a compreensão sobre a aprendizagem dos conhecimentos históricos em situações escolares e não escolares e que possibilite a investigação sobre processos que envolvam produzir conhecimento histórico, ensinar e aprender história. Além disso, é fundamental que o futuro professor compreenda a instituição escolar e seja capaz de estabelecer avaliação diagnóstica sobre seus estudantes em questões sociais, cognitivas e outras. ${ }^{1}$

Entendemos, ainda, que tais aprendizagens podem se estabelecer por meio de leituras de textos e pelos debates nas aulas das universidades. Mas podem ser aprendidas também com a vivência cotidiana na escola, amparada por um coletivo de professores de história com distintas experiências e referenciais: professores universitários, professores da escola básica (supervisores, nos termos do Pibid) e demais licenciandos. Entre tantas abordagens possíveis, o que procura oferecer o Subprojeto História do Pibid é a produção de conhecimentos que ampare a docência dos futuros professores, que contribua para o desenvolvimento profissional dos estudantes e professores das escolas públicas e que proporcione também aos professores universitários repensar suas práticas de ensinar a ensinar, com foco na finalidade primordial do Pibid nacional: "fomentar a iniciação à docência, contribuindo para o aperfeiçoamento da formação de docentes em nível superior e para a melhoria da qualidade da educação básica pública brasileira" (Brasil, 2013a, p.2).

O Pibid tem se constituído em laboratório que possibilita experimentar e refletir sobre práticas pedagógicas. Nestes escritos tratamos de refletir sobre uma dessas práticas que suscitou questionamentos, instigando-nos a escrever juntas. A questão que orienta este texto é a articulação entre as reflexões sobre o Ensino de História e a Teoria e Metodologia da História, a partir da mobilização de artefatos culturais contemporâneos em atividades de leitura e escrita na aula de história. Em outras palavras, interessa-nos compreender: como teoria e metodologia da história fundamentam a proposta desenvolvida pelos acadêmicos?

A proposta foi desenvolvida por três bolsistas do Pibid História na Escola Estadual Coronel Emilio Massot, localizada no centro de Porto Alegre, ${ }^{2}$ com uma turma de estudantes do ensino fundamental, objetivando desconstruir visões sobre o continente africano com base em diferentes narrativas históricas. Durante o primeiro semestre de 2014, os bolsistas acompanharam a professora de história responsável pela turma e puderam registrar o que os estudantes 
pensavam a respeito do continente africano. Isso aconteceu a partir de uma série de atividades, sendo a principal delas a apreciação, por parte dos estudantes, de uma série de imagens bastante diversas sobre o continente. Os estudantes surpreenderam-se por identificar apenas imagens relacionadas à pobreza ou à natureza selvagem com a África e desconsiderar imagens de regiões urbanizadas. Em encontros seguintes, os bolsistas deram continuidade ao tema utilizando documentários relacionados ao continente africano e, de certa forma, buscaram problematizar as representações dos estudantes. Segundo os bolsistas, a visão de um continente que só possui pobreza e doenças foi questionada, embora fosse necessário, ainda, romper com a visão dicotômica de uma África rica e uma África pobre. Na sequência das aulas, os bolsistas trabalharam com a história em quadrinhos (HQ) Tintim na África, que será mais bem detalhada no decorrer do artigo. A sequência foi concluída com atividades escritas e orais que demonstraram o desequilíbrio nas percepções dos estudantes, mas ainda com a manutenção de visões dicotômicas sobre o continente.

Para escrever as reflexões apresentadas neste artigo realizamos uma entrevista com os bolsistas do Pibid História que planejaram e efetivaram a proposta. Utilizamos também o planejamento dos bolsistas, o registro de nossas observações e a sistematização que eles realizaram para apresentar no X Salão de Ensino da UFRGS 2014. A pergunta que nos mobilizou a escrever este artigo não foi decidida a priori, como definição de um objeto de pesquisa. Nasceu da interlocução entre ensino, extensão e pesquisa proporcionada pela vivência no Pibid. Portanto, essas fontes de informação sobre a experiência ora em análise foram construídas após a finalização das atividades, especificamente para a escrita deste artigo.

$\mathrm{Na}$ sequência do artigo, três tópicos apresentam e discutem a experiência realizada pelos bolsistas à luz de referenciais aqui anunciados, além de refletir, ao final, sobre autoria de textos e refiguração de narrativas sobre presente e passado nas aulas de história.

\section{DOCÊNCIA-PESQUISA E APRENDIZAGEM DA HistóRIA}

O Pibid é um programa de iniciação à docência e, portanto, envolve pesquisa. Não aquela que busca a escola para confirmar hipóteses e enquadrar teorias e métodos, mas sim a pesquisa articulada ao ensino, marcada por pontos de luz e cegueira e, por isso, interroga o sentido do que se vê e por que se 
vê. O acento recai sobre os sujeitos, protagonistas do fazer pedagógico, que ensinam história em meio à vida: os pibidianos, imersos em suas tarefas acadêmicas, começam a interagir com o espaço escolar e questionar suas representações sobre esse lugar intenso e complexo; os professores das escolas são desafiados a planejar com bolsistas; os professores da universidade desenvolvem um intenso diálogo que abarca questionar tanto os saberes da experiência quanto os saberes da disciplina e, por fim, os estudantes do ensino fundamental e médio, que, por serem o fundamento principal da atividade de todos os outros, devem ser escutados e observados com atenção. A reflexão que acompanha esse percurso constrói hipóteses, questões de pesquisa e escritas que socializam a análise do vivido.

Os desafios principais têm sido: como planejar conteúdos em equipe, escolher os sentidos que se pretende construir nos conteúdos tratados em aula e suas abordagens mais apropriadas, adaptar-se ao tempo destinado às aulas de história, definir critérios para a escolha do que ensinar e, por fim, refletir e escrever sobre o ocorrido. Nossa proposição no Subprojeto História tem sido a de colocar-se em diálogo, interagir e construir propostas que sintetizem necessidades, expectativas e desejos dos professores, da turma de estudantes e dos bolsistas. A escola torna-se, para os futuros professores, além de um espaço de práticas, lugar de mobilização de interrogantes e de produção de conhecimentos complexos e inéditos. Conhecimentos e práticas que, posteriormente, se tornam motivo de reflexão teórica e de produção de textos de cunho acadêmico, como é o caso deste artigo.

Os debates sobre essa experiência nas reuniões de equipe do Pibid chamaram a atenção destas três autoras, que começaram a questionar-se sobre os referenciais mobilizados pelos bolsistas de iniciação à docência tanto na etapa de planejamento, quanto na avaliação de sua prática. Para isso, decidimos utilizar como fontes de estudo as observações sobre a prática, uma entrevista com os bolsistas envolvidos, os materiais didáticos utilizados, as respostas e reações dos estudantes e, por fim, o resumo escrito pelos bolsistas e apresentado no SIC. Seguem alguns excertos da entrevista em que informam sobre a atividade que motivou a escrita deste artigo. ${ }^{3}$

No começo, quando íamos nos reunir na escola para definir mais ou menos qual era a direção das nossas ações, juntamos interesse dos três ... A princípio a ideia 
era trabalhar com $\mathrm{HQ}$, mas como não somos ligados ao meio, tivemos que fazer uma pesquisa extensa ... Fica complicado colocar história em quadrinhos nos conteúdos, então se ampliou para leitura e interpretação, para darmos uma atenção específica para o autor da obra: de onde ele vem, problematizar quem produziu aquilo, o discurso que está presente nesta obra ... Então a gente pensou em apresentar alguns vídeos e a história em quadrinhos depois, para dar uma sequência, aprofundando a temática da África, mostrando elementos que talvez eles não conhecessem e no final [da aula] tentando fazer uma interpretação da história em quadrinhos. Foi bem importante, nesse ponto, porque a história em quadrinhos apresenta uma visão bem caricata. Então na questão da teoria, [tratar] da visão do autor sobre o Tintim na África, sobre aquela localidade. A gente achou que seria interessante trabalhar com os alunos essa interpretação dele. $\mathrm{O}$ rumo da atividade envolveu na verdade esse jogo de trazer algumas informações sobre o continente, mas também confrontando com os estereótipos ... O título original é Tintim no Congo e no Brasil foi traduzido como Tintim na África. O próprio título em francês é um estereótipo, pois [era] uma colônia belga que lá existia [com] diversos povos, mais variados; o que de certa forma é estranho. Mas trazer essa questão do título já é um elemento que foi importante para eles refletirem um pouco. (Relato de pesquisa, informação verbal)

Os pibidianos estavam envolvidos com turmas de $7^{\circ}$ ano e tinham duas preocupações iniciais: trabalhar com leitura e escrita e oferecer novas representações sobre o continente africano, ao mesmo tempo que ensinavam a questionar as representações correntes sobre a África. Assim, percebe-se que o primeiro interrogante dizia respeito aos objetivos primordiais da escola básica de Ensino Fundamental: consolidar e ampliar as habilidades de leitura e de escrita, tema presente nas discussões mais recentes das políticas públicas para a educação no Brasil (Brasil, 2013b). O segundo elemento se relacionava com um conhecimento histórico, isto é, a forma como o continente africano foi (e é) representado no senso comum. Havia aí, também, um elemento conectado à cidadania: era importante que, pela leitura, pela escrita e pela apreciação e questionamento de imagens, os jovens do $7^{\circ}$ ano pudessem modificar seus pré-conceitos sobre o continente africano. As Diretrizes Curriculares Nacionais para a educação básica (Brasil, 2013b, p.16), são enfáticas em conduzir os trabalhos da escola em direção a uma sociedade mais plural: 
Torna-se inadiável trazer para o debate os princípios e as práticas de um processo de inclusão social, que garanta o acesso e considere a diversidade humana, social, cultural, econômica dos grupos historicamente excluídos. Trata-se das questões de classe, gênero, raça, etnia, geração, constituídas por categorias que se entrelaçam na vida social - pobres, mulheres, afrodescendentes, indígenas, pessoas com deficiência, as populações do campo, os de diferentes orientações sexuais, os sujeitos albergados, aqueles em situação de rua, em privação de liberdade - todos que compõem a diversidade que é a sociedade brasileira e que começam a ser contemplados pelas políticas públicas.

As Diretrizes Curriculares Nacionais para a educação das relações étnico-raciais corroboram a responsabilidade da escola em promover novas narrativas e outras aprendizagens sobre a história e a cultura africana e afro-brasileira, sendo direito do todos os estudantes brasileiros conhecer, de forma respeitosa e positivada, a agência de negros e de negras na história do Brasil.

A escola tem papel preponderante para eliminação das discriminações e para emancipação dos grupos discriminados, ao proporcionar acesso aos conhecimentos científicos, a registros culturais diferenciados, à conquista de racionalidade que rege as relações sociais e raciais, a conhecimentos avançados, indispensáveis para consolidação e concerto das nações como espaços democráticos e igualitários. (Brasil, 2013b, p.501)

Como se nota, os porquês dos pibidianos estão em conformidade com a legislação nacional e também com as preocupações recentes do ensino de história, principalmente na literatura que trata do trabalho com questões socialmente vivas ou com problemas socialmente relevantes. Para Mével e Tutiaux-Guillon (2013, p.69-70), abrir as classes de história às controvérsias, aos debates e às questões socialmente vivas já é parte do que muitos professores de história procuram em suas aulas, justamente porque a sociedade está cercada de questões que são cientificamente e socialmente controversas. Imaginar que é possível ensinar história sem passar por essas questões seria o mesmo que pretender uma separação hermética entre os estudantes e a cidadania, o que estava longe das pretensões dos três futuros professores. As autoras citadas também acreditam que debater questões socialmente vivas não significa abandonar os temas curriculares estabelecidos, mas que tratá-las pode trazer outros 
movimentos para a organização dos temas de estudo. Entretanto, surgem dificuldades ao se estudar história por meio das controvérsias. Uma delas diz respeito às próprias expectativas dos estudantes, pois se espera, tradicionalmente, que os professores transmitam verdades e fatos e não que criem problemas a serem pensados:

Bem concretamente, este ensino sensível exige tempo, porque ele não pode se efetuar apenas em uma aula expositiva apoiada em documentos. Ele exige do professor um domínio suficiente dos saberes de referência e dos argumentos em debate ... Mas a dificuldade está presente também na natureza dos saberes: desde que damos lugar à controvérsia entre historiadores ou entre geógrafos ou à legitimidade de uma controvérsia entre cientistas e outros grupos sociais, o estatuto de verdade dos saberes escolares e de seus referenciais é colocado em questão... (Mével; Tutiaux-Guillon, 2013, p.76) ${ }^{4}$

Contudo, tendo em vista que um dos objetivos mais caros aos docentes universitários envolvidos no Subprojeto História do Pibid é a articulação entre as áreas de Ensino de História e Teoria e Metodologia da História, o que chama a atenção nos discursos dos licenciandos, sobre a sua própria prática, é a ausência de categorias oriundas do debate acadêmico nessa área para justificar os objetivos e a formatação das atividades propostas. Isso não implica, entretanto, que as suas intervenções utilizando os quadrinhos em sala de aula não sejam estruturadas de acordo com os parâmetros disciplinares da história. Somente uma avaliação superficial poderia suscitar o pensamento oposto. As categorias e os conceitos do conhecimento histórico que foram aqui mobilizados podem ter sido introjetados seja por uma discussão acadêmica muito bem assentada, seja pelo habitus adquirido pela prática disciplinar na universidade. Mesmo assim, embora presentes nas práticas dos pibidianos, conceitos como discurso, temporalidade e narrativa, bem como as técnicas da exegese hermenêutica ou da arqueologia dos saberes (Foucault, 1997), raras vezes são explicitamente mencionados em planejamentos ou relatos dos licenciandos, a não ser em resposta ao estímulo dos professores orientadores. Além dos conceitos teóricos, os bolsistas não mencionaram ter lido as DCN para a educação básica, para a educação das relações étnico-raciais, ou textos sobre história da África, tampouco sobre o uso de HQ na escola. Talvez esteja justamente aqui o papel dos professores universitários na construção de conhecimentos históricos e 
didáticos em coletivos que envolvem docentes com diferentes saberes e experiências.

Outro desafio docente diz respeito às formas pelas quais o professor trabalha pela construção do conhecimento com os estudantes. Afinal, os pibidianos já tinham opinião formada sobre a caricatura oferecida pela HQ e poderiam muito bem tê-la transmitido. Porém, ao não desejar essa imposição, poderiam conduzir a aula de forma que tudo o que os estudantes dissessem fosse válido, já que, sobre temas sensíveis, em geral, cada um tem a sua opinião, e o professor não deveria usar de sua suposta influência intelectual sobre os mais jovens... Com base nos relatos dos três licenciandos, encontrou-se um caminho interessante por conta de suas escolhas metodológicas, isto é, por estimular diferentes estratégias de leitura e de escrita a partir de elementos da cultura contemporânea: as fotos, os documentários e a HQ, sem abrir mão das necessárias exposições e contextualizações.

Eu queria trabalhar leitura e interpretação que na escola [durante] o estágio, havia notado dificuldade. ${ }^{5}$ Os alunos tinham dificuldade de leitura, de foco, às vezes liam uma frase, mas não conseguiam entender o sentido. O Raul queria trabalhar história em quadrinhos, que ele gosta bastante, [a partir] dessa lógica [proposta pelo] João, [com] diferentes modos de leitura, [para] que eles se interessem, porque não e só escrita, tem o desenho. É algo que chama bastante atenção. O Eric queria trabalhar a questão da música. De alguma forma, tudo envolve interpretação. (Relato de pesquisa, informação verbal)

A evidente preocupação com as formas de ensinar foi articulada pelos pibidianos com "a teoria” (e metodologia) da história, mesmo que esta tenha sido mencionada de forma mais rápida nos seus depoimentos. Sua presença no planejamento e concepção da atividade desenvolvida em aula se percebe na sujeição dos quadrinhos a uma prática de crítica documental, com o objetivo de propiciar a compreensão dos estereótipos veiculados nos quadrinhos dessa proposta específica. Os quadrinhos têm autoria e carregam marcas da sua produção, do espaço cultural que os originou, no qual circulavam representações da África e da Europa que se pode surpreender nas entrelinhas (ou entretraços) das aventuras de Tintim. Ao serem tomados como documentos submetidos ao questionário e crítica de professores/bolsistas e estudantes, tornaram-se 
"monumentos" ou fontes para a construção do conhecimento histórico em aula (Le Goff, 1996).

\section{MATERIAIS DIDÁTICOS, HISTORIOGRAFIA E ENSINO}

Eis que entra em cena um personagem criado pelo desenhista belga Georges Rémi, que assinava como Hergé: Tintim apareceu em 10 de janeiro de 1929, no jornal belga Le Vingtième Siècle. Tintim ${ }^{6}$ tornou-se sucesso internacional passando pela Guerra do Chaco, pela Revolução Russa e pela Guerra Fria, e também destacou a "escola belga" de quadrinhos com o estilo da linha clara, traços simples e espessura regular, com quase ausência de sombras (Moya, 1993). Os Smurfs são outro sucesso vindo da Bélgica. Desde a sua criação, Tintim foi publicado em quase sessenta idiomas em desenho animado, seriado de TV, peça de teatro, comédia musical e dois filmes, e em 2011 Steven Spielberg e Peter Jackson lançaram o filme As aventuras de Tintim.

O livro As Aventuras de Tintim - Tintim na África foi escrito na década de 1930 e propaga teorias raciais em circulação no período, que reafirmam a superioridade do europeu, as diferenças culturais entre europeus e os povos colonizados, e apresenta o europeu como o "civilizador" dos povos do continente africano. Nesse período, o Congo era ainda colônia da Bélgica, e o jornal para o qual Hergé trabalhava se revelava favorável ao imperialismo, lembrando que o contexto europeu apresentava ainda a ascensão de Hitler e de Mussolini.

A escolha de trabalhar o tema com base em Tintim na África vem ao encontro do que se escreve sobre o uso das histórias em quadrinhos em aula de história. Se o objetivo era questionar representações estereotipadas sobre o continente africano, a segunda obra de Hergé parece encaixar-se perfeitamente. Para Will Eisner (1989, p.13-14), “a compreensão de uma imagem requer uma comunidade de experiência”, isto é:

para que sua mensagem seja compreendida, o artista sequencial deverá ter uma compreensão da experiência de vida do leitor. É preciso que se desenvolva uma interação, porque o artista está evocando imagens armazenadas nas mentes de ambas as partes. O sucesso ou o fracasso deste método de comunicação depende da facilidade com que o leitor reconhece o significado e o impacto emocional da ima- 
gem. Portanto, a competência da representação e a universalidade da forma escolhida são cruciais.

Nesse sentido, os desenhistas de HQ acabam por recorrer à estereotipia, já que o espaço que lhes cabe para apresentar e desenvolver uma história exige que se criem desenhos que possam ser rapidamente identificados pelo leitor. Portanto, os traços devem ser escolhidos por seus autores pensando principalmente nas representações do público e não apenas nas suas. Vilson Gonçalves (2008, p.2), em estudo monográfico sobre a "Geografia do outro" nas HQs de Hergé, reforça esse argumento: “E uma vez que o título de 'primeira HQ' é, frequentemente, outorgado às gags de um estereotípico menino de gueto vestido num camisolão amarelo, careca e dentuço, acompanhado de um conjunto de pitorescos personagens, a alteridade é um tema pertinente às discussões que envolvem a linguagem das histórias em quadrinhos”.

A linguagem dos quadrinhos, como demonstrado na clássica obra de Eisner (1989), tem especificidades e, portanto, exige habilidades próprias de leitura e escrita. Esse é um aspecto a se pensar na reflexão dos pibidianos: desejavam exercitar com os estudantes de $7^{\circ}$ ano leitura e escrita de qual tipo de texto ou de imagem? Eles leram sobre Tintim e sabiam de seu contexto, por isso possibilitaram a leitura das especificidades da obra, mas estiveram atentos à linguagem quadrinística e a seu aspecto essencial: a sequência (Gonçalves, 2008, p.5)? Na sala de aula, o trabalho com o Tintim na África exigiu escolhas e adaptações e instigou a reflexão sobre as representações construídas sobre países africanos. Vejamos como os três pibidianos articularam sua aula perante tais interrogantes:

$\mathrm{Na}$ verdade, a gente viu que [a narrativa] era muito longa e não daria tempo. Selecionamos bem no meio da história em quadrinhos, para não pegar a introdução que se arrasta um pouco. Contamos um pouco da história e [focamos] no centro, onde esses estereótipos estão mais presentes e na cena final, que também é bem emblemática, quando eles ficam louvando o Tintim. A partir da leitura deles nós fomos de certa forma fazendo algum comentário ... tem uma parte que um trem bate no carro de Tintim e o carro não quebra, mas o trem quebra. Aí comentávamos "vocês não acham que é estranho? O trem quebra e o carro não? O certo seria o carro se destruir" ... O cachorro de Tintim ataca o leão e ganha [a briga]. Por que o curandeiro quer sacanear a própria população, dizendo que 
está mentindo? Então, dessa forma eles começaram a se dar conta de que sempre que Tintim se debatia com algo vindo da localidade, ele se dava melhor ... Eles foram percebendo que o único sujeito que parecia ter consciência, pensar, e ter ação era o Tintim. Os nativos eram ingênuos, não sabiam o que faziam, não sabiam o que estava acontecendo, mas foi bem interessante. (Relato de pesquisa, informação verbal)

Portanto, o trabalho com a leitura e a escrita na aula de história foi fundamental para que os estudantes do $7^{\circ}$ ano compreendessem os múltiplos objetivos da aula: debater representações de senso comum sobre a África e construir novas representações a partir do estímulo à leitura e escrita passando, dessa forma, pelo exercício da crítica histórica. Para Pereira e Seffner (2008, p.167), o trabalho com a leitura e a escrita na escola pública contemporânea passa pelo reconhecimento das diversidades "cultural, religiosa, étnica, econômica ... de geração, de classe social, de gênero e de orientação sexual, de nação e região...” como uma riqueza e não como um obstáculo, indo ao encontro dos objetivos de construção da sociedade democrática, que ainda exige a luta por direitos e a visibilidade de suas razões históricas. A leitura e a escrita tornam-se, assim, mais do que atividades rotineiras na classe, mas elementos que permitem organizar, descrever e mobilizar as referências oferecidas na aula (textos, imagens, fontes documentais etc.) e, posteriormente, sistematizar e expressar as aprendizagens conquistadas. Por esse meio, disputas e a mudança de ponto de vista do próprio Hergé foram também apresentadas aos estudantes do $7^{\circ}$ ano.

Ao seguir a ideia de "comunidade de experiência", exposta por Eisner (1989, p.13), pode-se pensar que Hergé desenhou para um público específico aquilo que este esperava ver. Mas nem todas as pessoas representadas em Tintim na África concordaram com os "tipos" criados e se opuseram, publicamente, a eles. Houve disputas e o próprio Hergé reconheceu os problemas nas suas primeiras obras.

Respondo que todas as opiniões são livres, incluindo a de pretender que eu sou racista... Há Tintim no Congo, admito-o. Isso passou-se em 1930. Do país eu só conhecia aquilo que as pessoas diziam na altura: "Os negros são crianças grandes... Felizmente para eles, nós estamos lá!, etc.. E eu desenhei estes africanos de acordo com esses critérios, no mais puro espírito paternalista que era o daquela época, na Bélgica. (Sadoul apud Gonçalves, 2008, p.21) 
Por intermédio da leitura dos quadrinhos e contraposição com outras informações, os estudantes tiveram a oportunidade de problematizar a obra e tornar seu pensamento um pouco mais complexo:

Mas acho que [foi] no final da atividade [que] nós comentamos que o Hergé sofreu alguns processos por causa dessa história em quadrinhos. Depois de toda essa discussão, comentamos que alguns cidadãos belgas de descendência africana processaram o Hergé por se sentirem lesados por isso ... Acho que por um tempo até se limitou a venda da história em quadrinhos, uma parcela de tempo se interrompeu, mas depois voltou ... Mas [foi] no final da atividade, para de certa forma não interferir na interpretação deles, o rumo da leitura. (Relato de pesquisa, informação verbal)

A gente trouxe umas leituras bem devagar ... a outra a gente perguntava por que o trem quebrou, porque o Tintim fala que o trem que quebrou é um tuctuc. Quando a gente falou "tuctuc" todo mundo começou a rir, depreciando. Foram vários questionamentos, vários problemas para eles perguntarem ... Fomos trazendo uns problemas para chamar atenção deles e no final comentamos isso, que foi uma obra que trouxe muita polêmica, apesar do Tintim ser muito querido por todos. (Relato de pesquisa, informação verbal)

Consultando Gonçalves (2008), como explicitaram os pibidianos, verifica-se que no diálogo com seus leitores, Hergé começou a se preocupar com a forma pela qual representava seus personagens e passou a pesquisar muito mais. As obras posteriores já não trazem a preocupação moralista católica e colonialista que marcou Tintim na África. Gonçalves (2008), ao acompanhar as demais obras de Hergé, demonstra que o autor se preocupou muito com a alteridade, o que se nota na forma como ele desenhava o Tintim: com traços simples e poucas possibilidades de expressão facial. Entretanto, tomava cuidado em apresentar para o leitor o ponto de vista do Tintim e, por isso, o personagem se define pelo outro que se apresenta à sua vista. Em suas últimas obras, Hergé criticava as grandes corporações e todos os que procuravam enriquecer às custas dos demais, alinhando-se, por exemplo, com os interesses dos camponeses latino-americanos ou dos chineses. 


\section{O ESTEREÓtIPO COMO DISCURSO: FUNÇÃO AUTOR E REFIGURAÇÃo NA SALA DE AULA DE História}

Ao desenvolverem a atividade sobre história da África tomando como recurso principal a história em quadrinhos protagonizada pelo personagem Tintim, os licenciandos do Pibid se envolveram na discussão de elementos caros ao debate sobre ensino de história na atualidade. O primeiro deles, a compreensão e superação dos estereótipos historicamente construídos acerca da África (Oliva, 2007; Silva, 2015); o segundo, o estímulo ao desenvolvimento da leitura e escrita como instrumentos privilegiados no desenvolvimento da capacidade crítica em geral. Ao tomarmos essa experiência como objeto de reflexão neste artigo, foi possível problematizar outros elementos mencionados de maneira menos enfática: o desenvolvimento da metodologia crítica, especificamente histórica, pelo confronto entre diferentes representações sobre a África, a investigação sobre a autoria de artefatos culturais, como as histórias em quadrinhos, e o exercício de leitura e escrita como possibilidade de refiguração narrativa da história.

Pensando os quadrinhos como integrantes de um discurso eurocêntrico reinante desde os primeiros contatos com o continente, passando pelos anos 1930, quando a história de Tintim foi composta, e chegando à atualidade, evidenciou-se como essas representações permanecem e reaparecem nas noções expostas pelos próprios estudantes do ensino básico ao manifestarem surpresa frente a imagens da África não condizentes com aquelas usualmente veiculadas em nosso contexto cultural.

O rumo dessa atividade sempre envolveu na verdade esse jogo de trazer algumas informações sobre o continente, mas também confrontando com os estereótipos, então desde o início com essa aula das imagens, que se tem uma pré-leitura que ela sempre faz para ver o que eles sabem. Então as imagens sempre envolviam, por exemplo, alguns lugares muito pobres que na verdade estão nos EUA e no Brasil, e não no continente Africano. Outros de paisagens de praias, hotéis, grandes construções, shoppings... Então foi feito sempre o jogo de ir mostrando e perguntando para eles onde era [aquela praia ou shopping], sem nenhuma legenda, sem nenhuma informação. E geralmente aconteceu o esperado: aquelas construções mais modernas, o shopping, [eram identificadas] como Miami, Recife ou Europa, e a pobreza era relacionada à África ... 
Isso é bem interessante porque eles tinham uma visão de que a África era animal, savana, que não era urbanizada. Inclusive num vídeo em que mostramos uma homenagem ao Mandela, dentro dum shopping, um aluno comentou muito surpreso: 'bah, mas na África tem shopping?'. Então certos elementos surgiram e de certa forma quebraram um pouco essa visão. (Relato de pesquisa, informação verbal)

Dessa forma, de maneira simultânea à "crítica externa" dos quadrinhos de Hergé, tomados como indícios de representações etnocêntricas, se desenvolve a sua "crítica interna", instrumentos consolidados de longa data na tradição historiográfica, que possibilitaram a compreensão de seu enredo e narrativa, presididos pela lógica da qualificação hierarquicamente inferior do outro. O recurso a imagens selecionadas e ordenadas pelos licenciandos e pela supervisora aprofunda e amplia essa compreensão ao propor o confronto entre diferentes testemunhos imagéticos do continente africano.

Para além da metodologia histórica tradicional, percebeu-se, no relato dos pibidianos, mesmo que não tenham sido explicitamente levantados, outros problemas teóricos observados na sua iniciação à docência. A história em quadrinhos Tintim na África foi abordada desde uma perspectiva que investigava não apenas o seu autor, o sujeito Hergé, mas a função autor, nos termos propostos por Michel Foucault (2013), pois os licenciandos trataram de um discurso sobre o continente, de forma semelhante ao que Edward Said (2007, p.29) propôs para o estudo do orientalismo. Sob esse prisma, a visão etnocêntrica sobre a África foi flagrada nos quadrinhos questionados pelos pibidianos, de forma que fossem tomados como fontes de um discurso que, no entanto, transcende os limites de seu enredo e de sua "autoria". ${ }^{7}$ A profundando a percepção dessa dispersão discursiva, a mesma visão denunciada nos quadrinhos foi surpreendida nas próprias leituras que as crianças fizeram das outras imagens por elas visualizadas. Sendo assim, ao apresentarem o quadrinista belga, criador de Tintim, os pibidianos extrapolaram a noção convencional de autoria para explorar também as condições de possibilidade das representações estereotipadas sobre a África.

Pensarmos nas atividades propostas como exercícios de "crítica documental", como visto, é apenas tangenciar a forma como foi problematizada a construção de sentido nas narrativas históricas pelos pibidianos em sala de aula. Por isso, podemos ainda propor que se considerem as "visões estereotipadas" 
do continente africano nas percepções dos estudantes e nos quadrinhos de Hergé como narrativas históricas dotadas de coerência interna e enredo. Consequentemente, essas "visões" podem ser compreendidas de acordo com as operações de pré-figuração, configuração e refiguração, da tríplice mimese proposta por Paul Ricoeur em Tempo e narrativa (1994). Nessa perspectiva, ao inserirem a leitura (tomada aqui no sentido amplo, que inclui entre seus objetos não somente o texto escrito, mas também as imagens) e crítica dos quadrinhos em sala de aula, os pibidianos contribuíram para criar condições de possibilidade para a construção de novas representações mediante refiguração das imagens estereotipadas da África.

Nesse contexto, deve ser sublinhado não apenas o que escreveu Hergé, nem somente o que os estudantes do ensino fundamental pensavam antes daquela aula; mas é importante compreender as representações dos quadrinhos como constructos que podem ser planejados, desmontados e remontados em outras bases, em consonância com os valores de cidadania já mencionados, presentes nas Diretrizes Curriculares Nacionais Gerais para a Educação Básica (2013b). Concretizou-se nesta atividade do Pibid, portanto, um dos objetivos mais perseguidos pelo ensino da história, inserido, como está, em certa "cultura da memória", que ele pretende tomar como objeto de sua atividade crítica (Guimarães, 2009, p.41). A memória sobre o continente africano compartilhada pelos estudantes da educação básica entra em contato com as ferramentas críticas do historiador, potencializando a construção de novos significados no saber escolar. Contudo, os professores nunca detêm controle sobre o resultado dos processos pedagógicos, algo lhe escapa, como em qualquer processo dialógico, como o de ensino:

São vários elementos que a gente quis trazer para de alguma forma aproximar deles e ver que a África não é tão distante, mas que vai gerar também estereótipos. A gente destrói alguns, mas cria outros. De certa forma a gente falou: "olha, tem riqueza cultural na África”, mas agora eles passavam a ver que mesmo que a gente comentasse que viver numa tribo ou descalço não significa pobreza ou algo ruim, eles geralmente viam a tribo Suazi como a África pobre e a África do supermercado como a rica, ou seja, aproximaram ao que eles veem, ao que estão acostumados. Então a gente desconstruiu que a África não é só pobre, mas agora ficou a ideia de que é uma parte pobre e outra rica. São probleminhas ainda a ser tratados, mas, enfim, são todos elementos que ajudavam depois para fazer um 
trabalho com a história do Tintim, analisar como que são retratados diversos povos que viviam no Congo. (Relato de pesquisa, informação verbal)

O circuito da tríplice mimese não é fechado; as refigurações operadas como resultado do trabalho didático em aula se oferecem mais como abertura do que definição/conclusão. Mas essa incompletude não pode ser vista - nem o foi, como se percebe nesse fragmento de depoimento - como falha ou obstáculo epistemológico à construção de conhecimento. Mesmo assim, na sua reflexão a respeito da atividade sobre a África em sala de aula, um dos pibidianos apontou lacunas de outra ordem: "Foi um desafio, porque além de não termos cadeira de História da África no colégio, aqui [na universidade] se vê muito pouca coisa e até fora da academia, então de certa forma nos desafiou a ir buscar elementos, a ter que pesquisar e descobrir" (Relato de pesquisa, informação verbal).

Em que pese a carência do tema História da África, observada pelos bolsistas em sua formação escolar e acadêmica, eles buscaram, pelo acionamento de teorias e métodos específicos do conhecimento histórico, problematizar aspectos fundamentais ao estudo desse tema, preparando o terreno para ampliar a sua compreensão. Convergiram, consequentemente, com a proposição de um ensino em que a história, "mais do que transmitir conteúdos através de uma boa didática ... teria que dar condições de criar as bases para o estabelecimento de relações com o passado que são necessariamente distintas segundo os presentes vividos" (Guimarães, 2009, p.49). Mesmo que não tenham identificado na sua experiência didática os debates teóricos que invocamos a partir da análise dos seus depoimentos, os pibidianos foram capazes de refletir sobre as potencialidades e limites das práticas e métodos históricos em sala de aula, reforçando a advertência de Lima (2009, p.153) contra avaliações que temem que os professores brasileiros não sejam capazes de reagir a visões equivocadas da história da África e dos africanos no Brasil.

De forma complementar, tal constatação nos instiga a refletir sobre a complexidade do ensino de teoria e metodologia da história na formação de professores. A qualidade do ensino de história, nessa perspectiva, consiste muito mais em operar com conceitos e debates historiográficos na elaboração de atividades problematizadoras do que na sua capacidade de invocá-los e citá-los (embora uma competência não inviabilize a outra). A nosso ver, é justamente 
a oportunidade aberta por programas como o Pibid, em que a iniciação à docência se encontra em contato com a agenda cotidiana das obrigações profissionais, mas ao mesmo tempo desatrelada dela, o que possibilitaria aprofundar o debate e a reflexão no que tange ao domínio e uso de conceitos e metodologias específicos do ofício do historiador na educação básica. Nesse sentido, é fundamental evitarmos cair na armadilha do discurso da "falta de teoria", pois somente comple(men)tando-se a atividade de iniciação à docência com a reflexão e escrita sobre ela é que chegaremos ao ponto de problematizar e compreender a complexidade das noções e práticas que ela abrange.

\section{CONSIDERAÇÕES FINAIS}

Avaliar a atividade é parte do ensinar e também elemento constituinte do fazer pesquisa na escola. O processo dialético que se estabelece entre o que se planeja e o que se efetiva no encontro com a turma de estudantes. O que acontece nesta trama entre a história ensinada e a história de cada um? Como o professor de história se constitui a partir da docência compartilhada no interior da escola?

Apesar de a intenção ser esta, de mostrar principalmente a questão da ingenuidade, como se eles [africanos] não tivessem história, o Tintim chega lá e fala o que eles têm que fazer. Mas de certa forma, juntando [a história em quadrinhos] com outros materiais, acho que conseguimos. Porque quando eles falam que "a gente achava que a África só tinha pobreza", "não conhecia nada sobre a África”, "não imaginava que tinha história”, não é [só] uma afirmação que eles fizeram, mas quando eles ficam surpresos e passam a ter um pouco mais de carinho para falar sobre o tema, eu acho que a gente conseguiu, chamou um pouco atenção para isso ...

É importante tu saber dividir o espaço, acho que isso é muito importante, que a gente acaba aprendendo isso. De vez em quando a gente tem muita coisa para passar para o aluno, mas daí se espera, porque o colega tem um pouco de conteúdo também. Então a gente aprende a dividir o espaço em sala de aula, que é muito rico.

Porque o curso vai te dando ideias que você não tem oportunidade de aplicar, então acaba se perdendo, porque vai ter só no estágio para aplicar, não vai conseguir 
aplicar em um mês, então o Pibid de certa forma é isso, tu vê uma coisa, vai construindo uma lógica para tu entrar em sala. (Relato de pesquisa, informação verbal)

A proposta, planejada e efetivada no âmbito do Subprojeto História da UFRGS, talvez indique pistas para pensarmos o valor político e a complexidade teórica das questões afetas ao ensino de história. Em estreita relação com essa preocupação, aparece associado outro interrogante que diz respeito a qual história e de que forma conhecê-la. Seria aquela que ensine competências e habilidades, como seleção e interpretação de fontes ou as mudanças e as permanências dos processos históricos? Como pensar um currículo que contemple não somente o conhecimento histórico canonizado pelo mundo ocidental? A pesquisa em história da África se desenvolve no Brasil desde o final dos anos 1950, e a legislação que obriga o seu ensino na educação básica surgiu "mais diretamente vinculada a reivindicações por direitos de cidadania e políticas de inclusão" (Lima, 2009, p.151). Sendo assim, na esteira das reflexões de Guimarães (2009), perguntamos, finalmente: como ensinar história a partir de preceitos teóricos e práticas consagradas no âmbito de sua disciplinarização moderna, em articulação com a dimensão política que lhe é subjacente desde então?

Certamente, é fundamental que o estudante da educação básica aprenda sobre o passado e o presente tomando como referência o ofício do historiador por meio da intervenção do professor, que seleciona fontes e estabelece as condições necessárias para que sua interpretação seja parte integrante do ensinar história. Com base nesse pressuposto, os acadêmicos/bolsistas trabalharam Tintim na África de forma que Hergé fosse percebido pelos estudantes da turma como um desenhista de seu tempo - de uma Bélgica colonizadora, reproduzindo a "mentalidade" da década de 1930 - mas também identificando continuidades desse discurso etnocêntrico em outros espaços e tempos. Sendo assim, a atividade proposta contribuiu também para se pensar e aprofundar a inclusão de povos indígenas, africanos, afrodescendentes, imigrantes atuais, desempregados, crianças, jovens, velhos e mulheres de segmentos populares, assim como todos os demais grupos e indivíduos alijados da distribuição de bens materiais e simbólicos. Em vista da dimensão política que lhe é intrínseca, a história continua tendo como compromisso a criação de condições que permitam a distribuição 
mais igualitária de todos esses bens, assim como, obviamente, a garantia do acesso aos conhecimentos acumulados pela humanidade no seu percurso.

\section{REFERÊNCIAS}

BRASIL. Diretrizes Curriculares Nacionais Gerais da educação básica. Brasília: MEC, SEB, DICEI, 2013b. Disponível em: http://portal.mec.gov.br/index. php?option=com_docman\&task=doc_download\&gid=13448\&Itemid; Acesso em: 17 maio 2015.

BRASIL. Coordenação de Aperfeiçoamento de Pessoal de Nível Superior (Capes). Portaria n.96, de 18 de julho de 2013. Regulamento do Programa Institucional de Bolsa de Iniciação à Docência. Diário Oficial da União, Brasília, DF, Seção 1, 23 jul. 2013, p.11. 2013a. Disponível em: http://pesquisa.in.gov.br/imprensa/jsp/visualiza/ index.jsp?jornal=1\&pagina=11\&data=23/07/2013; Acesso em: 17 maio 2015.

BRASIL. Conselho Nacional de Educação. Resolução n.2, de 1 de julho de 2015. Define as Diretrizes Curriculares Nacionais para a formação inicial em nível superior (cursos de licenciatura, cursos de formação pedagógica para graduados e cursos de segunda licenciatura) e para formação continuada. Diário Oficial da União, Brasília, DF, Seção 1, 2 jul. 2015, p.8. Disponível em: http://pesquisa.in.gov.br/ imprensa/jsp/visualiza/index.jsp?jornal=1\&pagina $=8 \&$ data $=02 / 07 / 2015 ;$ Acesso em: 21 set. 2015.

BRASIL. Ministério da Educação. Parecer n. 3/2006. Reexame do Parecer CNE/CP n. 5/2005, que trata das Diretrizes Curriculares Nacionais para o Curso de Pedagogia. Disponível em: www.mec.org.br; Acesso em: 20 out. 2015.

COLÉGIO ESTADUAL CORONEL AFONSO EMILIO MASSOT. Projeto Político Pedagógico Triênio 2015-2017. Porto Alegre, 2015. (Mimeogr.).

EISNER, Will. Quadrinhos e arte sequencial. São Paulo: Martins Fontes, 1989.

FOUCAULT, Michel. A arqueologia do aber. Rio de Janeiro: Forense Universitária, 1997.

. O que é um Autor? In: MOTTA, Manoel B. (Org.) Estética: literatura e pintura, música e cinema. 3.ed. Trad. Inês A. D. Barbosa. Rio de Janeiro: Forense Universitária, 2013. (Coleção Ditos e Escritos, III).

GONÇALVES, Vilson A. M. Geografia do Outro: representações de alteridade em As Aventuras de Tintim, de País dos sovietes a O ídolo roubado. Monografia (Especialização em história, Arte e Cultura) - Departamento de História, Universidade Estadual de Ponta Grossa (UEPG). Ponta Grossa, 2008.

GUDMUNDSDÓTTIR, Sigrun; SHULMAN, Lee. Conocimiento Didáctico en Ciencias Sociales. Profesorado. Revista de currículum y formación del profesorado, Granada, v.9, n.2, p.1-12, 2005. 
GUIMARÃES, Manoel Luiz S. Escrita da história e Ensino da história: tensões e paradoxos. In: ROCHA, Helenice; MAGALHÃES, Marcelo; GONTIJO, Rebeca (Org.) A escrita da história escolar: memória e historiografia. Rio de Janeiro: Ed. FGV, 2009. p.35-50.

LE GOFF, Jacques. Documento/monumento. In: História e memória. 4.ed. Campinas: Ed. Unicamp, 1996. p.535-553.

LIMA, Mônica. Aprendendo e Ensinando história da África no Brasil: desafios e possibilidades. In: ROCHA, Helenice; MAGALHÃES, Marcelo; GONTIJO, Rebeca (Org.) A escrita da história escolar: memória e historiografia. Rio de Janeiro: Ed. FGV, 2009. p.149-164.

MÉVEL, Yannick; TUTIAUX-GUILLON, Nicole. Didactique et enseignement de l'Historie-géographie au Collège et au Lycée. Paris: Publibook, 2013.

MONTEIRO, Ana M. A história Ensinada: algumas configurações do saber escolar. História e ensino, Londrina, v.9, p.37-62, out. 2003. Disponível em: http://www. uel.br/revistas/uel/index.php/histensino/article/view/12075/10607; Acesso em: 20 maio 2015.

Professores de história: entre saberes e práticas. Rio de Janeiro: Mauad, 2007.

MOYA, Álvaro de. História da história em quadrinhos. São Paulo: Brasiliense, 1993. p.60-62.

NÓVOA, António. Para uma formação de professores construída dentro da profissão. Revista de Educación, La formación de profesores de Educación Secundaria, Madrid, n.350, p.203-218, set./dez. 2009.

OLIVA, Anderson. Lições sobre a África: diálogos entre as representações dos africanos no imaginário Ocidental e o ensino da história da África no Mundo Atlântico (1990-2005). Tese (Doutorado em História) - Universidade de Brasília. Brasília, 2007. Disponível em: http://repositorio.unb.br/handle/10482/1132; Acesso em: 16 out. 2016.

PEREIRA, Nilton; SEFFNER, Fernando. História, leitura e escrita no Ensino Médio. In: PEREIRA, Nilton et al. (Org.) Ler e escrever: compromisso no Ensino Médio. Porto Alegre: Ed. UFRGS, 2008. p.165-180.

RICOEUR, Paul. Tempo e narrativa. Tomo 1. Trad. Constança Marcondes Cesar. Campinas: Papirus, 1994.

RÜSEN, Jörn. História Viva. Teoria da história III: formas e funções do conhecimento histórico. Trad. Estêvão de Rezende Martins. Brasília: Ed. UnB, 2007.

SAID, Edward. Orientalismo: o Oriente como invenção do Ocidente. Trad. Rosaura Eichenberg. São Paulo: Companhia das Letras, 2007.

SILVA, Gizelda C. da. A história da África e da Cultura Afro-Brasileira: os saberes e fazeres dos professores. In: ZAMBONI, Ernesta; GALZERANI, Maria C.; 
PACIEVITCH, Caroline (Org.) Memória, sensibilidades e saberes. Campinas: Alínea, 2015. p.193-208.

TINTIM completa 80 anos de aventuras. Universo HQ. Reportagem de Sérgio Codespoti. 12 jan. 2009. Disponível em: http://www.universohq.com/materias/tintim-completa-80-anos-de-aventuras/; Acesso em: 10 maio 2015.

\section{NOTAS}

${ }^{1}$ Esta breve síntese sobre aspectos mínimos a serem contemplados na formação inicial de professores passa por nossa compreensão das exigências legais (BRASIL, 2015) e por apropriações críticas de autores como GUDMUNDSDÓTTIR e SHULMAN (2005), NÓVOA (2009) e MONTEIRO (2003), entre outros.

${ }^{2}$ Segundo o PPP do Colégio Estadual Afonso Emilio Massot (COLÉGIO, 2015), a instituição localiza-se em bairro próximo ao centro da cidade, caracterizado por atividades de tipo terciário de pequeno, médio e grande porte. O documento informa características socioeconômicas dos estudantes e de suas famílias, que moram em zonas diversas de Porto Alegre e em municípios da região metropolitana. Constata-se que as famílias são constituídas por trabalhadores de baixa e média renda: "As condições socioeconômicas exigem dos pais uma dedicação intensa ao trabalho, dificultando um acompanhamento efetivo das atividades escolares". Verifica-se, ainda, que muitos dos estudantes, principalmente do Ensino Médio, já estão inseridos no mercado de trabalho, geralmente como estagiários.

${ }^{3}$ Em dezembro de 2014 gravamos uma entrevista com os três bolsistas nas dependências da universidade, solicitando que contassem essa experiência em particular e refletissem sobre ela, que já havia sido apresentada no Salão de Ensino da UFRGS, em 2014. Todos assinaram termo de consentimento livre e esclarecido.

${ }^{4}$ No original: "Très concrètement, cet enseignement sensible demande du temps, parce qu'il ne peut s'effectuer par un cours dialogué étayé de documents. Il demande à l'enseignant une maîtrise suffisante des savoirs de référence et des arguments du débat ... Mais la difficulté est aussi dans la nature des savoirs: dès lors qu'on fait place à la controverse entre historiens ou entre géographes ou à la légitimité d'une controverse entre scientifiques et autres groupes sociaux, le statut de vérité des savoirs scolaires et de leurs références savantes est mis en question..." (tradução nossa).

${ }^{5} \mathrm{O}$ depoente havia feito estágio na mesma escola em que atuou posteriormente com bolsista do Pibid.

${ }^{6}$ Os primeiros nove álbuns foram: (1) As Aventuras de Tintim repórter do "Petit Vingtième" no País dos Sovietes (publicado em tiras, no jornal Le Petit Vingtième, em 1929, e como álbum, em 1930); (2) As Aventuras de Tintim - Tintim no Congo, volume lançado anteriormente no Brasil com o título Tintim na África (publicado em tiras, no jornal Le Petit Vingtième, em 1930, e como álbum, em 1931); (3) As Aventuras de Tintim - Tintim na Améri- 
ca (publicado em tiras, no jornal Le Petit Vingtième, em 1931, e como álbum, em 1932); (4) As Aventuras de Tintim - Os Charutos do Faraó (publicado em tiras, no jornal Le Petit Vingtième, em 1932, e como álbum, em 1934); (5) As Aventuras de Tintim - O Lótus Azul (publicado em tiras, no jornal Le Petit Vingtième, em 1934, e como álbum, em 1936); (6) As Aventuras de Tintim - O Ídolo Roubado (publicado em tiras, no jornal Le Petit Vingtième, em 1936, e como álbum, em 1937); (7) As Aventuras de Tintim - A Ilha Negra (publicado em tiras, no jornal Le Petit Vingtième, em 1937, e como álbum, em 1938); (8) As Aventuras de Tintim - O Cetro de Ottokar (publicado em tiras, no jornal Le Petit Vingtième, em 1938, e como álbum, em 1939); (9) As Aventuras de Tintim - O Caranguejo das Pinças de Ouro, volume lançado anteriormente no Brasil com o título O Caranguejo das Tenazes de Ouro (publicado em tiras, em 1940, no Le Soir Jeunesse, e como álbum, em 1941). Informações disponíveis em: http://www.universohq.com/materias/tintim-completa-80-anos-de-aventuras/; Acesso em: 10 maio 2015.

${ }^{7}$ Referimo-nos aqui ao percurso que um documento perfaz até tornar-se fonte, passando incontornavelmente pelo questionário do professor/historiador. As perguntas dirigidas aos quadrinhos foram orientadas por um problema historiográfico: que imagem da África se constitui neste suporte?

Artigo recebido em 25 de outubro de 2016. Aprovado em 26 de dezembro de 2016. 